\title{
Obesity and Crohn's disease: what comes first, the egg or the chicken?
}

\author{
Paulo Gustavo KOTZE
}

Received 16/6/2017 Accepted 19/6/2017

Kotze PG. Obesity and Crohn's disease: what comes first, the egg or the chicken? Arq Gastroenterol. 2017;54(3):268.

HEADINGS - Crohn disease. Ulcerative colitis. Obesity.

\section{Dear sir,}

It was with great interest that we read the paper entitled "Body composition in patients with Crohn's disease and ulcerative colitis", recently published in Arquivos de Gastroenterologia, by Back IR et al. In this interesting cross-sectional study in 141 inflammatory bowel disease (IBD) patients, using the body mass index (BMI), $40.74 \%$ of Crohn's disease (CD) and $52.87 \%$ of ulcerative colitis (UC) were considered as overweight or obese. Most of the patients from the study were in remission. Active IBD lead to worsening in nutritional parameters, mostly in CD patients as compared to UC, mainly in inflammatory markers as Haemoglobin and erythrocyte sedimentation rate $(\mathrm{ESR})^{(1)}$.

Obesity represents a real challenge in IBD patients. Recent data demonstrated that overweight patients could have earlier secondary loss of response rates during biological therapy ${ }^{(5)}$. Moreover, there is solid evidence that demonstrates higher rates of postoperative complications in $\mathrm{CD}$ patients with higher BMI as compared to eutrophic subjects ${ }^{(3)}$.

The relation between CD and obesity is currently being studied, as there might be a relation in common pathways with the development of mesenteric fat that may be related to gut inflammation ${ }^{(2)}$. Intra-abdominal fat can be an important common characteristic of both obesity and CD due to its immune properties that could link the innate immune system to obesity-related metabolic disorders, specifically to gut inflammation ${ }^{(2,3)}$.
Apart from the molecular level, obesity rates are also increasing in non-CD patients ${ }^{(4)}$. Westernization of diet, lack of exercise and sedentary lifestyle contribute to that. On the other hand, the increase in obesity rates in CD patients is also notable over the last decades, and a question mark on what comes first, could be raised. The cause-consequence relation between $\mathrm{CD}$ and obesity is poorly understood. Does obesity cause CD? Or are they both a consequence of an increase in western diet and sedentarism, well known risk factors for both entities? Do CD patients become obese due to the improvement in the mucosal inflammation, caused by medication, what increases absortion of nutrients? There is still need for more data on the exact pathogenesis that can possibly link obesity and CD. Currently, the egg or the chicken classic question (which comes first?) could be applied in this issue, as it is unknown if obesity is a cause or a consequence of $\mathrm{CD}$, and vice versa.

What is known is that obesity is being observed more frequently in IBD outpatient clinics $^{(1,6)}$. This emphasizes the alarm lead by this important paper by Back et al., that demonstrated important rates of overweight and obese patients in an IBD cohort, defined with strict and detailed technical measurements. These findings also emphasize the importance of a dietitian in the IBD multidisciplinary team, as patients' outcomes can probably be impaired with obesity. The need for attention in weight gain, not only in malnutrition, is currently a modern need in IBD therapy, and can affect the prognosis of the disease and response to different therapies.

Kotze PG. Obesidade e doença de Crohn: o que vem primeiro, o ovo ou a galinha? Arq Gastroenterol. 2017;54(3):268.

DESCRITORES - Doença de Crohn. Colite ulcerativa. Obesidade.

\section{REFERENCES}

1. Back IR, Marcon SS, Gaino NM, Vulcano DSB, Dorna MS, Sassaki LY. Body composition in patients with Crohn's disease and Ulcerative colitis. Arq Gastroenterol. 2017;54:109-114.

2. Bertin B, Desreumaux P, Dubuquoy L. Obesity, visceral fat and Crohn's disease. Curr Opin Clin Nutr Metab Care. 2010;13:574-80.

3. Ding Z, Wu XR, Remer EM, Lian L, Stocchi L, Li Y, McCullough A, Remzi FH, Shen B. Association between high visceral fat area and postoperative complications in patients with Crohn's disease following primary surgery. Colorectal Dis. 2016;18:163-72.
4. GBD 2015 Obesity Collaborators. Health Effects of Overweight and Obesity in 195 Countries over 25 Years. N Engl J Med. 2017 Jun 12. doi: 10.1056/NEJMoa1614362. [Epub ahead of print].

5. Harper JW, Sinanan MN, Zisman TL. Increased body mass index is associated with earlier time to loss of response to infliximab in patients with inflammatory bowel disease. Inflamm Bowel Dis. 2013;19:2118-24.

6. Moran GW, Dubeau MF, Kaplan GG, Panaccione R, Ghosh S. The increasing weight of Crohn's disease subjects in clinical trials: a hypothesis-generatings time-trend analysis. Inflamm Bowel Dis. 2013;19:2949-56. 